\title{
Functionalized Graphene as a Catalytic Counter Electrode in Dye-Sensitized Solar Cells
}

\author{
Joseph D. Roy-Mayhew, David J. Bozym, Christian Punckt, and Ilhan A. Aksay* \\ Department of Chemical and Biological Engineering, Princeton University, Princeton, New Jersey 08544, United States
}

$\mathrm{D}$ ye-sensitized solar cells (DSSCs) have received much attention as an alternative to silicon-based solar cells due to their potential low cost, easy fabrication, and respectable energy conversion efficiency (over 10\%). ${ }^{1,2}$ In typical DSSC architectures, the photon-induced oxidation of a dye occurs at a $\mathrm{TiO}_{2}$ photoanode, while the reduction of the redox species used to regenerate the dye occurs at the counter electrode. The standard redox couple used for dye regeneration, iodide/ triiodide $\left(\mathrm{I}^{-} / \mathrm{I}_{3}{ }^{-}\right)$, has unmatched performance but typically requires a platinum catalyst in DSSC operation. ${ }^{3-5}$ Platinum has high catalytic activity toward $\mathrm{I}_{3}{ }^{-}$reduction and is sufficiently corrosion-resistant to iodo species present in the electrolyte. ${ }^{6-9}$ However, since platinum is a precious metal, much incentive exists to develop DSSC counter electrodes using cheaper, abundant materials. Extensive research has, for example, been performed on using carbonaceous materials for the counter electrode because they are low cost, corrosion resistant, and electrically conductive. ${ }^{9-18}$ While graphite has poor catalytic activity toward the reduction of $\mathrm{I}_{3}{ }^{-}$, its high surface area analogs, such as carbon black and carbon nanotubes, have been shown to be quite effective and in some cases even exceeded the performance of platinum. ${ }^{18-20}$ Very recently, graphene composites have emerged as potential catalysts for DSSC cathodes, due to graphene's exceptional surface area and conductivity. ${ }^{21-23}$ Hong et al., for example, have used a chemically reduced graphite oxide derived graphene/poly(3,4ethylenedioxythiophene) poly(styrenesulfonate) (PEDOT:PSS) composite and achieved efficiencies of $4.5 \%$, comparable to their platinum control cell at $6.3 \%$. It has www.acsnano.org
ABSTRACT When applied on the counter electrode of a dye-sensitized solar cell, functionalized graphene sheets with oxygen-containing sites perform comparably to platinum (conversion efficiencies of 5.0 and $5.5 \%$, respectively, at $100 \mathrm{~mW} \mathrm{~cm}{ }^{-2} \mathrm{AM} 1.5 \mathrm{G}$ simulated light). To interpret the catalytic activity of functionalized graphene sheets toward the reduction of triiodide, we propose a new electrochemical impedance spectroscopy equivalent circuit that matches the observed spectra features to the appropriate phenomena. Using cyclic voltammetry, we also show that tuning our material by increasing the amount of oxygen-containing functional groups can improve its apparent catalytic activity. Furthermore, we demonstrate that a functionalized graphene sheet based ink can serve as a catalytic, flexible, electrically conductive counter electrode material.

KEYWORDS: graphene $\cdot$ dye-sensitized solar cell $\cdot$ counter electrode . iodide/triiodide catalyst $\cdot$ charge-transfer resistance $\cdot$ flexible

been suggested that oxygen-containing functional groups might be responsible for the observed catalytic performance of carbonaceous electrode materials, while the impact of the degree of material functionalization on apparent electrocatalytic performance has not been studied in detail. ${ }^{16,24}$

In this paper, we provide a thorough analysis of DSSC cathodes based on functionalized graphene sheets (FGSs), a type of defective graphene currently synthesized at the industrial scale ${ }^{25}$ via the thermal exfoliation of graphite oxide (GO), detailed elsewhere. ${ }^{26,27} \mathrm{FGSs}$ have a large surface area (up to $2630 \mathrm{~m}^{2} \mathrm{~g}^{-1}$ ) and contain lattice defects and oxygen-containing functional groups, such as hydroxyls, carbonyls, and epoxides, as shown in Figure 1. ${ }^{27-29}$ The amount of oxygen-containing groups can be tuned by thermal processing of the material, thereby changing its carbon to oxygen (C/O) ratio. ${ }^{26}$ Thermal treatment up to $\sim 1000^{\circ} \mathrm{C}$ decreases the number of oxygencontaining functional groups on the surface of the sheets and increases the FGS conductivity. Furthermore, annealing at temperatures above $\sim 1500^{\circ} \mathrm{C}$ causes healing of lattice defects. ${ }^{28,30} \mathrm{An}$ advantage of

\author{
*Address correspondence to \\ iaksay@princeton.edu. \\ Received for review July 14, 2010 \\ and accepted September 22, 2010. \\ Published online October 12, 2010. \\ $10.1021 / \mathrm{nn} 1016428$ \\ (c) 2010 American Chemical Society
}




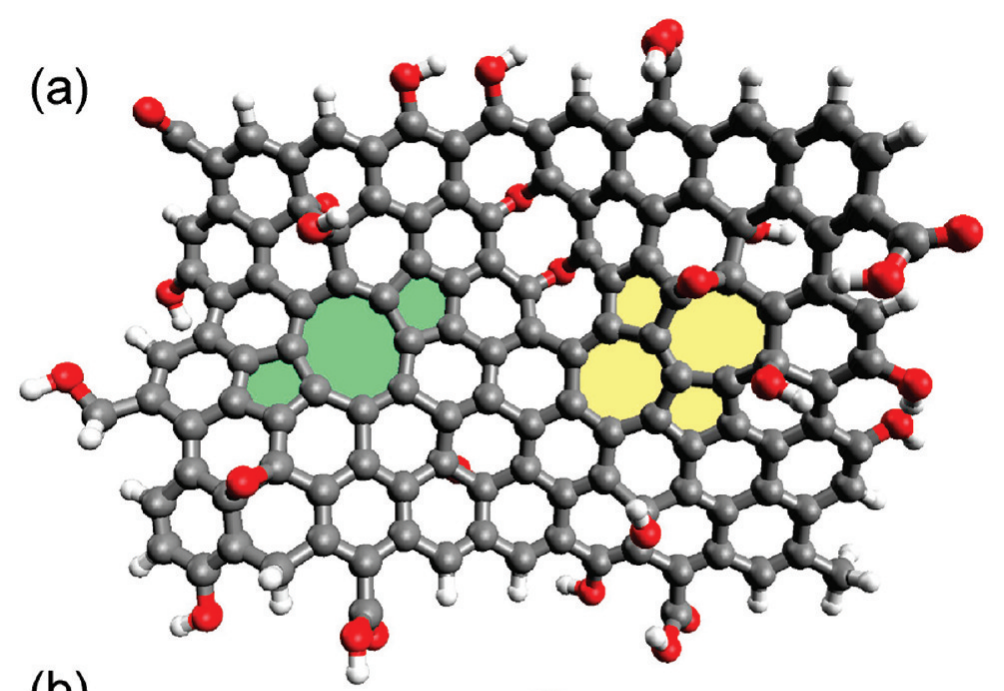

(b)

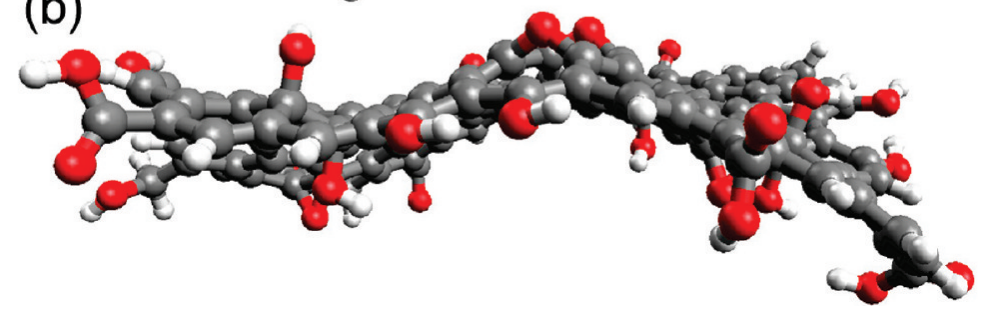

Figure 1. (a) Schematic of functional groups and lattice defects on an FGS. Epoxides and hydroxyls are on both sides of the graphene plane, while carbonyl and hydroxyl groups are at the edges. A 5-8-5 defect (green), and a 5-7-7-5

(Stone-Wales) defect (yellow) are also shown. Carbon atoms are gray, oxygen atoms are red, and hydrogen atoms are white. (b) Side view emphasizing the topography of the sheet. These schematics are representative of the functionalities on FGSs but not an actual sheet, which would measure on the order of $1 \mu \mathrm{m}$ across.

our material is that we can systematically adjust the C/O ratio of the FGS to examine its effect on the catalytic activity of the material. To distinguish the compositions of FGSs, we designate them as $\mathrm{FGS}_{x}$, where $x$ denotes the $\mathrm{C} / \mathrm{O}$ ratio.

In the following, we first show that FGSs can function as the catalytic counter electrode material in a fully assembled DSSC with a performance similar to that of platinum. Based on these results and supplementary electrochemical impedance spectroscopy (EIS) measurements on the FGS counter electrode itself, in which we vary the applied bias as well as electrolyte viscosity and concentration, we propose a new approach to interpret impedance spectra for porous carbon electrodes. We use this interpretation to properly quantify the charge-transfer resistance of FGS counter electrodes. To support our EIS data, we then investigate the catalytic activity of FGSs in more detail using cyclic voltammetry (CV). Although the optimization of FGS counter electrodes is beyond the scope of this work, we explore the effect of functionalization as measured by C/O ratio as well as the effect of electrode morphology on the apparent catalytic activity of FGSs. Finally, we utilize the industrial scale production of the material to demonstrate DSSC operation using a commercially available ${ }^{25}$ FGS-based ink that can be cast on nonconductive elastomeric surfaces as the counter electrode.

\section{RESULTS AND DISCUSSION}

\section{Photovoltaic Performance of DSSCs with FGS Counter}

Electrodes. In Figure 2, we show the current density-voltage curves and summarize the device characteristics for DSSCs with $\mathrm{FGS}_{13}$ and platinum counter electrodes. As detailed in the Experimental Methods Section, we fabricate FGS counter electrodes via thermolysis of surfactant and polymer in an FGS-surfactant-polymer network. Cells employing $\mathrm{FGS}_{13}$ reach an efficiency $(\eta)$ of $4.99 \%$, which is more than $90 \%$ that of platinum-based cells ( $\eta=5.48 \%$ ), where efficiency is defined as the cell's maximum power output divided by the input power from the

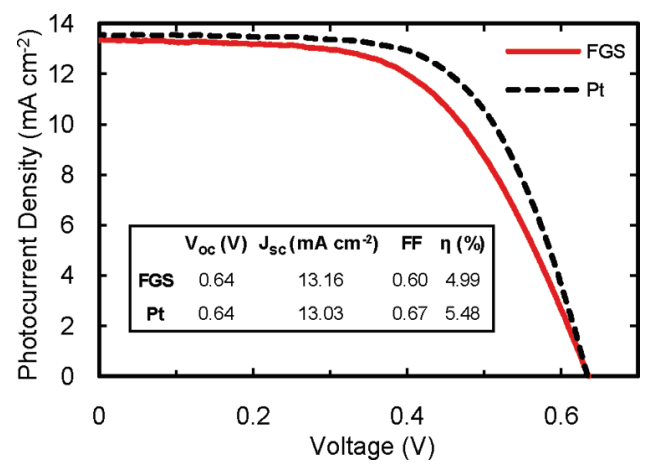

Figure 2. J-V curve characteristics of DSSCs using thermally decomposed chloroplatinic acid and $\mathrm{FGS}_{13}$ counter electrodes measured in lodolyte AN-50 electrolyte. Active area is $0.39 \mathrm{~cm}^{2}$. 
(a)

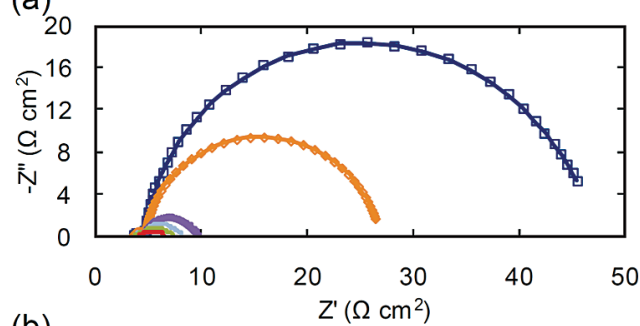

(b)

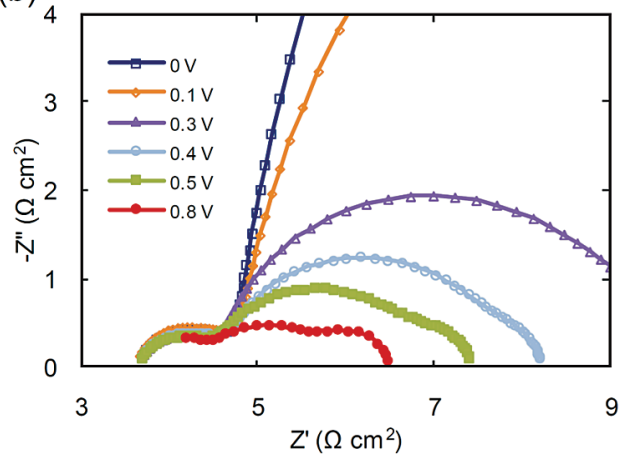

Figure 3. (a) Impedance spectra for $\mathrm{FGS}_{13}$ symmetric cell at various applied biases. (b) An expansion of the high-

frequency region. The legend in (b) is for (a) as well. At low bias the spectra have two semicircles. As bias is increased, a third semicircle becomes more prominent.

light source. Both types exhibit an open circuit voltage $\left(V_{\text {oc }}\right)$ of $0.64 \mathrm{~V}$ and a similar short circuit current density $\left(J_{\mathrm{sc}}\right)$ of about $13 \mathrm{~mA} \mathrm{~cm}^{-2}$. The fill factor (FF), the ratio of the maximum power obtainable in the device to the theoretical maximum power [FF $=\left(J^{*} \times V^{*}\right) /\left(J_{\text {sc }} \times V_{\text {oc }}\right)$, where $J^{*}$ and $V^{*}$ are the current density and voltage, respectively, at the cell's maximum power output] is lower for the $\mathrm{FGS}_{13}$ cells accounting for their lower efficiency. In view of these encouraging results with functionalized graphene as the counter electrode, below, we analyze our FGS electrodes electrochemically to quantify their catalytic activity and determine how the material could be processed or further modified to improve device efficiency.

Quantifying FGS Catalytic Activity by EIS. EIS has been widely used to study the reduction of $\mathrm{I}_{3}{ }^{-}$on platinum electrodes. $^{6-8,31}$ Specifically, a well-supported equivalent circuit has proved a valuable tool in understanding the platinum counter electrode in DSSC operation. This equivalent circuit has also been applied to measurements performed with carbon-based electrodes without a robust understanding of its appropriateness, ${ }^{9,24,32,33}$ as we demonstrate below with our results on FGS-based counter electrodes.

Figure 3 shows EIS data of FGS electrodes in a symmetric sandwich cell configuration at various applied biases. Following IUPAC convention, $Z^{\prime}$ and $Z^{\prime \prime}$ are the real and imaginary parts of the impedance, respectively. As bias is applied, the high-frequency semicircle remains unchanged, while the lower-frequency semicircle shrinks until eventually three semicircles are visible.
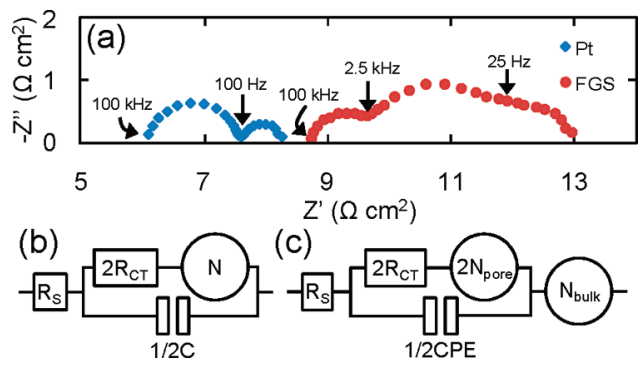

(c)

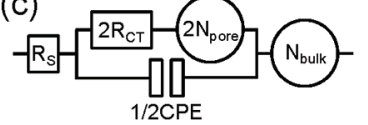

Figure 4. (a) Impedance spectra of symmetric cells from 100 $\mathrm{kHz}$ to $1 \mathrm{~Hz}$ at $0.8 \mathrm{~V}$. Left: Thermally decomposed chloroplatinic acid with (b) conventional equivalent circuit. Due to electrode roughness, a constant phase element (CPE) is often used instead of an ideal capacitance. Right: $\mathrm{FGS}_{13}$ with (c) proposed equivalent circuit. $R_{\mathrm{S}}$ : series resistance; $R_{\mathrm{CT}}$ : chargetransfer resistance of one electrode; $C$ : capacitance of one electrode; $N_{\text {bulk: }}$ : Nernst diffusion impedance between the electrodes; CPE: constant phase element of one electrode; $N_{\text {pore: }}$ Nernst diffusion impedance within electrode pores.

We use the traditional equivalent circuit for a sandwich cell configuration detailed by Hauch and Georg to interpret our impedance spectra. ${ }^{7}$ This equivalent circuit is a resistor in series with a resistor-capacitor (RC) pair and a Nernst diffusion element which results in a Nyquist plot with two semicircles offset from the origin as shown in Figures $4 a$ and b. Accordingly, the ohmic serial resistance $\left(R_{\mathrm{s}}\right)$ can be determined from the onset of the first semicircle $(\sim 100 \mathrm{kHz})$. Charge-transfer resistance $R_{C T}$ and double layer capacitance $(C)$ of the electrode surface give rise to the first semicircle (midfrequency: $100-0.1 \mathrm{kHz}$ ). Diffusion of electrolyte species which is affected by the separation between the electrodes causes the second semicircle (low frequency: less than $10 \mathrm{~Hz}$ ) which is described by the Nernstian diffusion element $(N)$.

Based on this approach, we find that $R_{\mathrm{CT}}$ should be $0.64 \pm 0.07 \Omega \mathrm{cm}^{2}$ for an FGS electrode, whereas the $R_{\mathrm{CT}}$ for a platinum electrode should have a value of 0.79 $\pm 0.02 \Omega \mathrm{cm}^{2}$. The lower charge-transfer resistance would imply a greater FF and higher $\eta$ in solar cell operation for the FGS electrode. However, our device performance data (Figure 2) show the opposite effect, suggesting that the EIS interpretation based on platinum electrodes may not be appropriate for our system.

To further demonstrate the inappropriateness of the model, we analyze impedance spectra recorded under bias. We expect that, as bias is applied to the system, the Nernst diffusion impedance increases, corresponding to a depletion of $\mathrm{I}_{3}{ }^{-}$at the cathode. ${ }^{7}$ Furthermore, we expect that the catalytic charge-transfer resistance decreases exponentially until a diffusion-limited region is reached, as predicted by simple Butler-Volmer kinetics. ${ }^{34}$ These effects have been previously demonstrated for platinum ${ }^{7}$ and reproduced by us. However, our FGS electrodes do not follow this behavior, providing additional evidence toward the inappropriateness of applying the traditional equivalent circuit to our system. As deviation from the traditional equivalent circuit is only evident under applied bias, it is possible that research- 


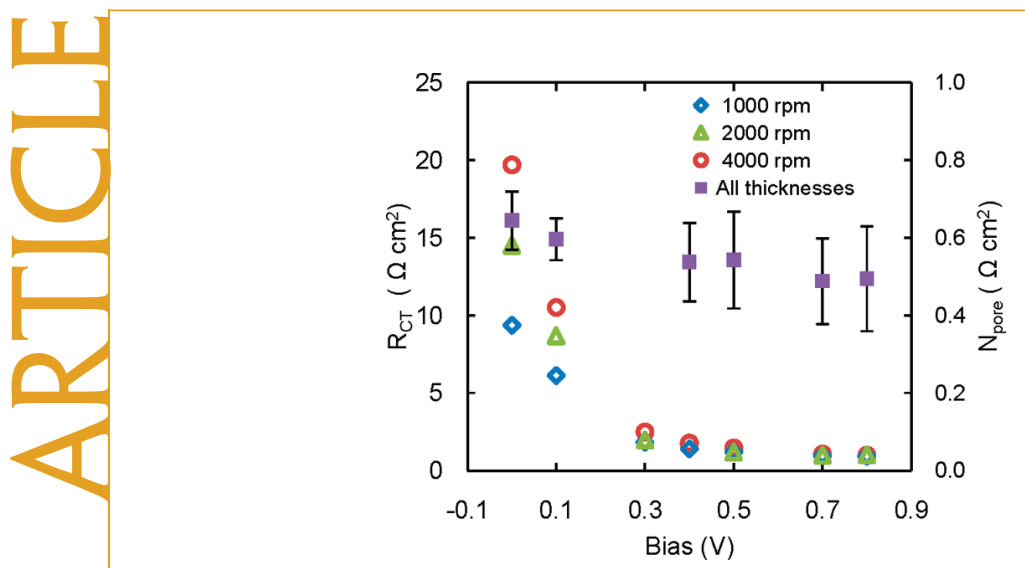

Figure 5. $R_{\mathrm{CT}}$ and $N_{\text {pore }}$ for symmetric $\mathrm{FGS}_{13}$ cells of different thicknesses at various applied biases. Open symbols use left axis, and closed squares use right axis. Cells spun at higher rates have less material and, thus, less surface area than those spun at slower rates.

ers have misinterpreted their data in previous studies and have underestimated the charge-transfer resistance associated with their carbon electrodes. This misinterpretation could explain inconsistencies between device performance and EIS charge-transfer resistance data.

To more accurately explain our results, we propose a model for porous FGS electrodes (and likely other porous carbon electrodes) seen in Figure $4 c$ in which we attribute the high-frequency semicircle $(100-2.5 \mathrm{kHz})$ to a second Nernst diffusion impedance resulting from diffusion through the electrode pores $\left(N_{\text {pore }}\right)$. The middle semicircle $(2500-25 \mathrm{~Hz}$ ) represents the chargetransfer resistance and the capacitance of the FGS/ electrolyte interface $\left(R_{\mathrm{CT}}, \mathrm{CPE}\right)$. As in the traditional approach, the low-frequency semicircle is determined by bulk Nernst diffusion $\left(N_{\text {bulk }}\right)$, while the high-frequency offset determines the serial resistance $\left(R_{\mathrm{s}}\right)$.

To further analyze the validity of our model, we performed studies varying the FGS layer thickness, bias, electrolyte concentration, and electrolyte viscosity. To create FGS electrodes of varying thicknesses, FGS suspensions were spin coated on conductive glass substrates at three different spin rates. These electrodes were then assembled in a symmetric sandwich cell configuration, and the impedance measurements were taken at biases from 0 to $0.8 \mathrm{~V}$. As seen in Figure $5, R_{\mathrm{CT}}$ initially decreases exponentially with increasing bias as expected due to faster kinetics at higher overpotential. The thicker the $\mathrm{FGS}_{13}$ layer, the lower the resistance at low bias; however, the impedance for all thicknesses collapses to a single curve at high voltages. Meanwhile, $\mathrm{N}_{\text {pores }}$ decreases only slightly with bias since $\mathrm{I}^{-}$and $\mathrm{I}_{3}^{-}$ are similar in size and carry equal charge.

To further prove the diffusive nature of the first and third semicircles in our impedance data, we varied two parameters, as shown in Figure 6: (i) the viscosity, by adding a gelling agent poly(ethylene glycol) (PEG) and (ii) the concentration of the electrolyte species. Both increasing viscosity and decreasing electrolyte concentra-

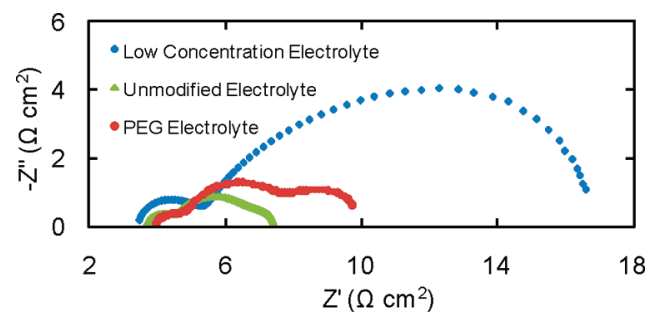

Figure 6. Impedance spectra at $0.5 \mathrm{~V}$ for $\mathrm{FGS}_{13}$ symmetric cells with (i) low-concentration electrolyte: $0.05 \mathrm{M}$ Lil and 5 $\mathrm{mM} \mathrm{I}_{2}$, (ii) unmodified electrolyte: $0.5 \mathrm{M} \mathrm{Lil} \mathrm{and} 0.05 \mathrm{M} \mathrm{I}_{2}$, and (iii) PEG electrolyte: $0.5 \mathrm{M} \mathrm{Lil,} 0.05 \mathrm{M} \mathrm{I}_{2}$, and $25 \mathrm{mM}$ PEG 8000 in acetonitrile.

tion should increase $N_{\text {bulk }}$ and $N_{\text {pore }}$. A higher viscosity leads to a lower diffusion coefficient; and reducing the species concentration would reduce the electrolyte conductivity and place the system in a regime in which depletion of $\mathrm{I}_{3}{ }^{-}$could be significant. Using our EIS interpretation, these effects are indeed observed as a large increase in impedance of the low-frequency semicircle is visible with the PEG electrolyte, and $N_{\text {pore }}$ even dominates over $R_{C T}$ in the low species concentration sample. A similar effect is seen with the high-frequency semicircles as well.

In order to confirm the symmetrical nature of our cells, and, in particular, to confirm that the mid- and low-frequency semicircles each do not represent a contribution from individual electrodes which behave differently due to an unequal distribution of applied bias in the sandwich cell, we performed experiments in a classical three-electrode configuration, thus only analyzing a half cell. A silver wire was used as a reference between the two symmetric cells, with Celgard 2320 membranes used as spacers between the electrodes. In this setup, only the impedance associated with one electrode $\left(R_{\mathrm{CT}}, N_{\text {pore }}\right)$ and about half of the bulk diffusion $\left(N_{\text {bulk }}\right)$ and series resistance $\left(R_{\mathrm{s}}\right)$ would be measured. At all frequencies, the impedance in this three-electrode setup was about half that for the same cell connected in the traditional two-electrode setup. This result dismisses the possibility that the mid-frequency semicircle represents one electrode, while the low-frequency semicircle represents the other electrode, and further supports our model. Due to the corrosive nature of the electrolyte and complications arising from trying to prevent the reference from contacting the electrodes, this setup was only used for this comparative purpose and not for our quantitative measurements.

Using the appropriate equivalent circuits for platinum and our porous FGS samples, we determined the charge-transfer resistance associated with the redox couple. At zero bias, the charge-transfer resistance of a thermally decomposed chloroplatinic acid cell is $0.79 \Omega \mathrm{cm}^{2}$, which agrees well with literature values $\left(0.5-1.8 \Omega \mathrm{cm}^{2}\right)$, and is well below the $10 \Omega \mathrm{cm}^{2}$ level needed for high-performance cells. ${ }^{7,9,35,36}$ At zero bias, the $\mathrm{FGS}_{13}$ based counter electrodes performed relatively poorly, with a charge-transfer resistance of 


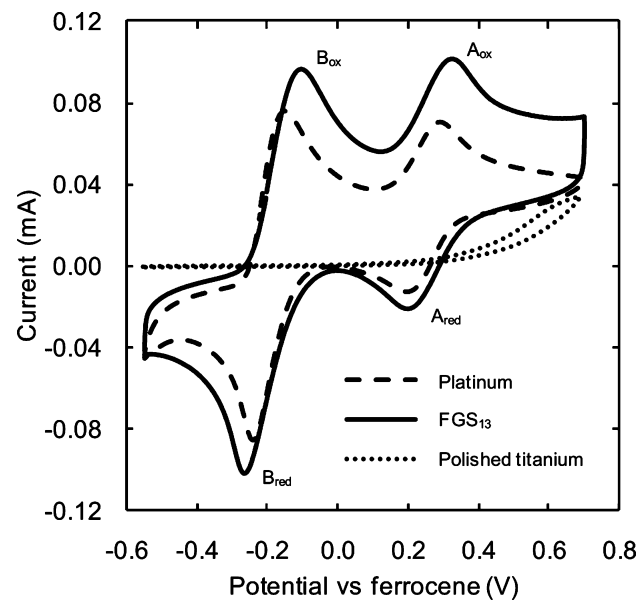

Figure 7. Cyclic voltammograms obtained at a scan rate of $50 \mathrm{mV} \mathrm{s}^{-1}$ for the oxidation and reduction of the $\mathrm{I}_{2} / \mathrm{I}_{3}{ }^{-}$and $\mathrm{I}^{-} /$ $\mathrm{I}_{3}{ }^{-}$redox couples using polished titanium rod electrodes loaded with $12 \mu \mathrm{g}$ of platinum and $\mathrm{FGS}_{13}$. The voltammogram for a blank polished titanium rod is also shown. $A_{o x}$ and $A_{\text {red }}$ indicate the oxidative and reductive peaks for the $\mathrm{I}_{2} / \mathrm{I}_{3}{ }^{-}$ couple, while $B_{\text {ox }}$ and $B_{\text {red }}$ indicate the oxidative and reductive peaks for the $\mathrm{I}^{-} / \mathrm{I}_{3}{ }^{-}$couple.

$9.4 \Omega \mathrm{cm}^{2}$ recorded for cells spun at $1000 \mathrm{rpm}$. These values are based on the geometric surface area of the electrode and not the accessible surface area due to the porosity of the material. However, at applied bias, the resistance approaches that of platinum. For instance at a $0.5 \mathrm{~V}$ bias, the charge-transfer resistance of thermally decomposed chloroplatinic acid was measured to be $0.78 \Omega \mathrm{cm}^{2}$, while that of the $\mathrm{FGS}_{13}$ cell spun at $1000 \mathrm{rpm}$ was $1.2 \Omega \mathrm{cm}^{2}$. The greater charge-transfer resistance for $\mathrm{FGS}_{13}$ compared to platinum, especially at low bias, is consistent with the decrease in the fill factor and efficiency of DSSCs using FGS electrodes. However, based on the EIS data alone, we cannot determine whether the greater charge-transfer resistance is due to an intrinsically lower catalytic activity for the material or to inadequate accessible surface area.

Investigating Catalytic Activity of FGS Using CV. To distinguish between specific catalytic activity and surface area effects, we obtained cyclic voltammograms for $\mathrm{FGS}_{13}$ and platinum-modified titanium electrodes (Figure 7). To probe exclusively the catalytic contribution of FGSs, we analyzed films created from drop casting an ammoniated water $(\sim \mathrm{pH} 11) \mathrm{FGS}$ suspension onto an inert polished titanium rod. Additionally, to resolve the peaks, we used an electrolyte concentration 10 times lower than that used in a DSSC. Scanning from -0.5 to $0.75 \mathrm{~V}$ vs Ag/ $\mathrm{Ag}^{+}$(for ferrocene, the redox potential is $55 \pm 5 \mathrm{mV}$ on all samples) two pairs of peaks are observed for both materials, similar to what has been reported for comparable systems in the literature. ${ }^{14,22,37}$ Although the exact charge-transfer mechanisms are not fully understood, literature attributes peaks $A_{o x}$ and $A_{\text {red }}$ to the oxidation and reduction of $\mathrm{I}_{2} / \mathrm{l}_{3}{ }^{-}$and peaks $\mathrm{B}_{\mathrm{ox}}$ and $\mathrm{B}_{\text {red }}$ to the oxidation and reduction of $\mathrm{I}^{-} / \mathrm{I}_{3}{ }^{-} .38-40$ Since the counter electrode of a DSSC is responsible

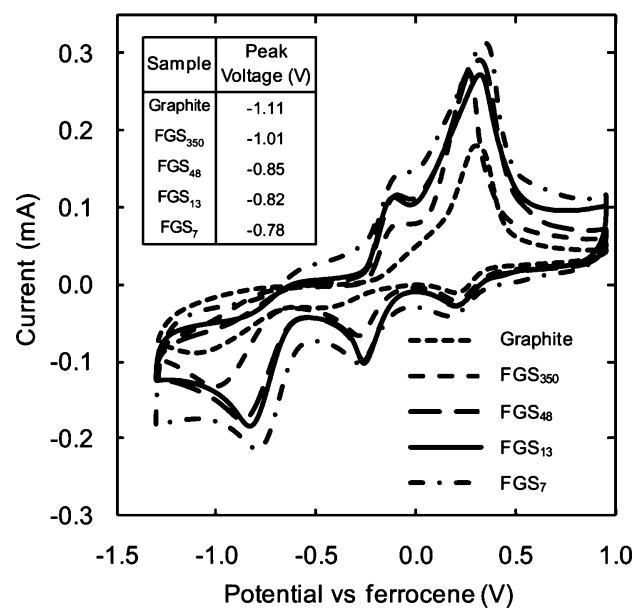

Figure 8. CVs obtained at a scan rate of $50 \mathrm{mV} \mathrm{s}^{-1}$ for polished titanium rod electrodes loaded with $12 \mu \mathrm{g}$ of FGS with C/O ratios of approximately $7,13,48$, and 350 . A voltammogram for graphite is also shown for reference. The positions of the third reductive peak (most negative potential) are included in the insert for each material. The identities of the specific redox reactions responsible for third peaks are currently unknown.

for catalyzing the reduction of $\mathrm{I}_{3}^{-}$to $\mathrm{I}^{-}$, the characteristics of peaks $B_{o x}$ and $B_{\text {red }}$ are at the focus of our analysis.

The standard electrochemical rate constant of a redox reaction is negatively correlated with the peak to peak separation $\left(E_{\mathrm{pp}}\right) \cdot{ }^{41}$ Thus, with $\mathrm{CV}$, we rely mostly on $E_{\mathrm{pp}}$ between $\mathrm{B}_{\mathrm{red}}$ and $\mathrm{B}_{\mathrm{ox}}$ to gauge the catalytic activity of the modified electrodes. For electrodes modified with platinum and $\mathrm{FGS}_{13}$, we measure $E_{\mathrm{pp}}$ values of 90 and $150 \mathrm{mV}$, respectively. The platinum-modified electrode is thus more catalytic toward the reaction due to a lower $E_{\mathrm{pp}}$, which supports our EIS model and can explain the higher device efficiencies using a platinumbased counter electrode material.

The catalytic activity of $\mathrm{FGS}_{13}$ may be due to its large density of lattice defects and oxygen-containing functional groups..$^{42}$ Therefore, it may be possible to further decrease $E_{\mathrm{pp}}$ of FGSs by tuning these potentially catalytic sites. Capitalizing on the $\mathrm{C} / \mathrm{O}$ ratio tunability of FGSs, Figure 8 shows the cyclic voltammograms for FGS-coated titanium electrodes with $\mathrm{C} / \mathrm{O}$ ratios varying from 7 to 350 within a voltage window from -1.25 to $1 \mathrm{~V}$ vs $\mathrm{Ag} / \mathrm{Ag}^{+}$. We selected the wide scanning window to fully investigate the electrochemistry of our material without degrading the solvent, acetonitrile. A third pair of peaks is then observed for all materials at a highly negative overpotential, near $-0.65 \mathrm{~V}$ vs ferrocene; however, the corresponding oxidation peak cannot be resolved as it is superimposed by the oxidation peak of the $\mathrm{I}_{2} / \mathrm{I}_{3}{ }^{-}$redox pair $\left(\mathrm{A}_{\mathrm{ox}}\right.$ in Figure 7 ). Little improvement is seen in the $E_{\mathrm{pp}}$ of the middle reduction and oxidation peaks, $\mathrm{B}_{\text {ox }}$ and $\mathrm{B}_{\text {red }}$ for $\mathrm{FGS}_{7}$ compared to the previously used $\mathrm{FGS}_{13}$, implying that both materials have similar catalytic activity for the reduction of $\mathrm{I}_{3}{ }^{-}$. For $\mathrm{FGS}$ with $\mathrm{C} / \mathrm{O}$ ratios greater than $13, E_{\mathrm{pp}}$ increases with increasing $\mathrm{C} / \mathrm{O}$ ratio, suggesting that FGSs 
with fewer oxygen-containing functional groups may yield electrodes with larger charge-transfer resistances and DSSCs with lower efficiencies. As the C/O ratio is reduced, the third reduction peak shifts toward more positive potentials (see inset of Figure 8). Recently, this peak was reported by Fang et al. who examined an electrode coated with a nanostructured carbonaceous material. ${ }^{24}$ They speculated, and our data support, that the third pair of peaks was caused by functional groups on the surface of the carbon material. Although they did not specify the identities of these groups, the observation that the peak shifts with $\mathrm{C} / \mathrm{O}$ ratio suggests that they contain oxygen (e.g., hydroxyls or epoxides).

For devices with appreciable fill factors, to obtain maximum power during DSSC operation, the potential at the counter electrode is typically -0.1 to $-0.3 \mathrm{~V}$ vs the electrolyte redox potential $\left(E_{\text {redox }} \sim-0.14 \mathrm{~V}\right.$ vs ferrocene). While this potential is too positive to drive the reactions occurring at the third reduction peak at maximum rate, it could be expected that the reaction onset associated with the third peak occurs early enough (i.e., at sufficiently positive potential) to increase the reaction rate at a relevant operating potential. To increase this contribution further, the reduction peak needs to be shifted to more positive potentials, possibly by further decreasing the $\mathrm{C} / \mathrm{O}$ ratio of the FGSs. However, the conductivity of FGSs decreases with decreasing C/O ratio, an effect that competes with the positive potential shift. An electrode with C/O ratio much less than 7 likely will not be conductive enough for use as a catalytic counter electrode. For example, $\mathrm{FGS}_{2}$ electrodes clearly have poor catalytic activity as they exhibit a resistor-like CV profile when tested. Although more study is required, it may be possible to improve the catalytic activity of our material without further decreasing the $\mathrm{C} / \mathrm{O}$ ratio if a specific oxygen-containing functional group were found to be primarily responsible for catalysis. Increasing the concentration of this specific functional group while eliminating inactive oxygen-containing functionalities would preserve conductivity at higher degrees of functionalization. Alternatively, the catalytic activity may be improved by increasing the lattice defect concentration, but more studies are needed to determine this effect.

Impact of FGS Electrode Morphology on Apparent Catalytic Activity. We have shown that the C/O ratio is correlated with apparent catalytic performance. However, this could be caused not only directly through an increase of the intrinsic catalytic activity of the material but also indirectly through a change in electrode morphology. Specifically, theoretical studies suggest that porosity can significantly affect the apparent catalytic properties of an electrode. ${ }^{43-45}$ Our electrode-coating process results in FGS films that are highly porous. ${ }^{42}$ As seen in the scanning electron microscope (SEM) images of Figure 9 , adjusting the number of oxygen-containing functional groups on FGSs alters the drying dynamics of
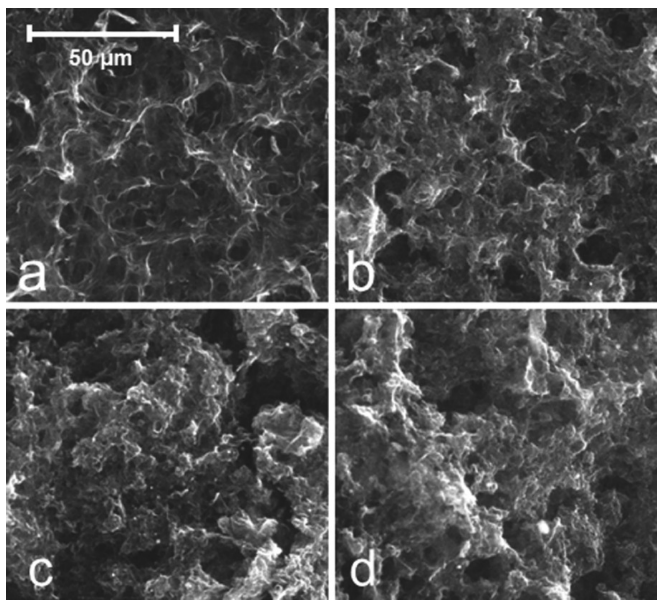

Figure 9. SEM images of $12 \mu \mathrm{g}$ films of (a) $\mathrm{FGS}_{7}$, (b) $\mathrm{FGS}_{13}$, (c) $\mathrm{FGS}_{48}$, and (d) $\mathrm{FGS}_{350}$ drop cast from ammoniated water suspensions on polished titanium substrates. The scale bar in (a) applies to all images.

the material and results in different FGS packing. At a low C/O ratio, the material forms an open, layered structure with pores on the micrometer scale. As the $\mathrm{C} / \mathrm{O}$ ratio increases, the FGSs form coarser films as a result of increased agglomeration. Thus, based on the different morphologies of the FGS films, it is reasonable to expect that electrodes made from different types of FGS may exhibit different porosity. ${ }^{42}$

We use CV to analyze how increasing the loading of $\mathrm{FGS}_{13}$ influences the apparent catalytic activity of the material. Our CV data support the predictions of the theoretical models on the role of porosity. ${ }^{45}$ Furthermore, to characterize the effect of electrode morphology on the apparent catalytic activity of the $\mathrm{FGS}_{13}$, we have examined the dependence of the peak current $\left(I_{\mathrm{p}}\right)$ on scan rate $(v)$ and performed CV measurements with coatings of varying thickness.

$I_{p}$ for the oxidation and reduction of $\mathrm{I}^{-} / \mathrm{I}_{3}{ }^{-}$measured as a function of $(v)$ deviates slightly from the ideal behavior expected for semi-infinite diffusion of the involved redox species $\left(I_{p} \propto v^{1 / 2}\right)$, as shown in Figure 10. The deviation is prominent at low scan rates where the magnitude of both the oxidation and the reduction peaks decreases. Electrode porosity might account for this since at small scan rates the electrolyte can become depleted of the involved redox species. ${ }^{41}$

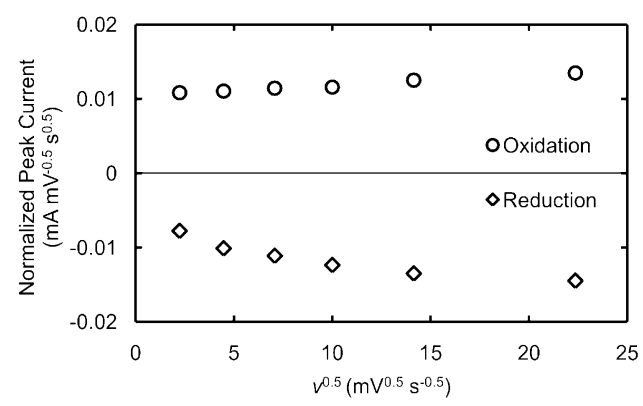

Figure 10. The peak current response versus the square root of the scan rate for oxidation and reduction of the $\mathrm{I}^{-} /$ $\mathrm{I}_{3}{ }^{-}$redox couple. 


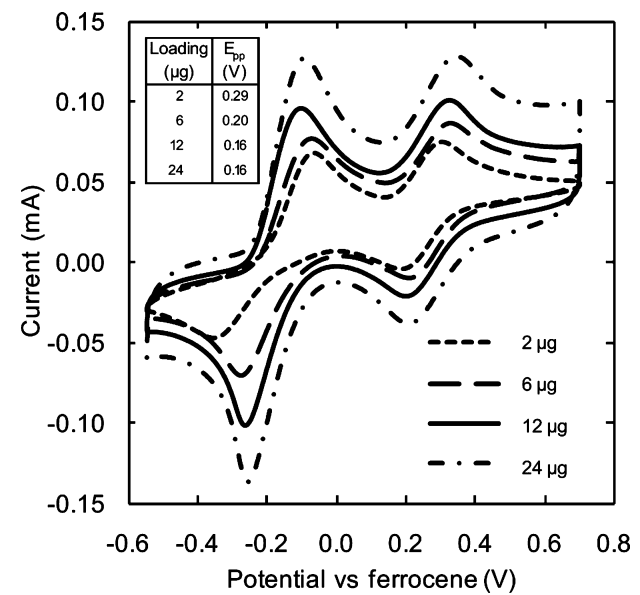

Figure 11. Cyclic voltammograms obtained at a scan rate of $50 \mathrm{mV} \mathrm{s}^{-1}$ for polished titanium rod electrodes loaded with $2,6,12$, and $24 \mu \mathrm{g} \mathrm{FGS}{ }_{13} . E_{\mathrm{pp}}$ for the oxidation and reduction of the $\mathrm{I}^{-} / \mathrm{I}_{3}-$ redox couple for each loading is given in the insert.

The effect is more pronounced for the reduction peak since the concentration of $\mathrm{I}_{3}{ }^{-}$is considerably lower than the concentration of $\mathrm{I}^{-}$.

An additional indication for an impact of electrode morphology is the dependence of $E_{\mathrm{pp}}$ and $I_{\mathrm{p}}$ on the thickness of the electrode coating (Figure 11). The geometric areas of all tested electrodes are identical. Therefore, higher loadings correspond to thicker films. As seen in the insert of Figure $11, E_{\mathrm{pp}}$ of the $\mathrm{I}^{-} / \mathrm{I}_{3}{ }^{-}$redox reaction is much larger for the electrode with $2 \mu \mathrm{g} \mathrm{FGS}_{13}$ than for those with higher loadings. The reduction potential (peak $B_{\text {red }}$ ) experiences a significant positive shift as the $\mathrm{FGS}_{13}$ loading increases. At the same time, the peak current (and also the capacitive background current) increases indicating a higher accessible surface area. Since we do not know the exact relation between electrode loading and accessible surface area, we cannot analyze the data quantitatively. However, the observed behavior is reminiscent of cyclic voltammograms simulated for electrodes of varying porosity. ${ }^{45}$ We then conclude that the observed differences in the apparent catalytic activity of the tested electrodes are probably in part affected by differences in electrode morphology. This is of particular importance when comparing different electrode materials (see Figure 8) as different materials may result in different electrode porosity and, thus, different apparent catalytic activities.

FGS-Based Inks As Flexible Counter Electrodes. As demonstrated in Table 1, in addition to replacing platinum, FGS-based counter electrodes can be printed onto a va-

TABLE 1. Photovoltaic Characteristics of DSSCs with Vorink and Platinum Counter Electrodes

\begin{tabular}{lcccc}
\multicolumn{1}{c}{ sample } & $\boldsymbol{V}_{\text {oc }}(\mathbf{V})$ & $\boldsymbol{J}_{\text {sc }}\left(\mathbf{m A ~ c m}^{-2}\right)$ & FF & $\boldsymbol{\eta}(\%)$ \\
\hline Vor-ink P3 & 0.70 & 8.14 & 0.66 & 3.75 \\
Vor-ink P10 & 0.71 & 7.77 & 0.70 & 3.83 \\
Pt on FT0 & 0.73 & 7.89 & 0.72 & 4.16 \\
\hline
\end{tabular}

www.acsnano.org

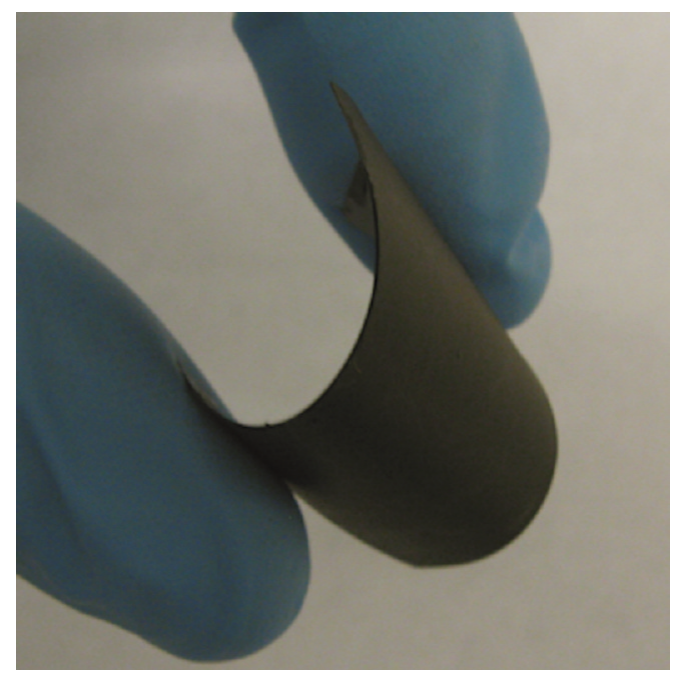

Figure 12. Vor-ink P10 film cast on mylar.

riety of substrates, including those which are insulating, heat sensitive, and flexible. Cells produced using counter electrodes made from FGS-based conductive inks (Vor-ink) ${ }^{25}$ cast onto mylar (Figure 12) have efficiencies within $10 \%$ of cells using platinum-coated fluorinedoped tin oxide glass (FTO). Both Vor-ink P3 and FTO electrodes have a resistivity of $\sim 10 \Omega \mathrm{sq}^{-1}$, while Vorink P10 electrode has a resistivity of $\sim 5 \Omega \mathrm{sq}^{-1} .25$ This difference does not appear to have a large effect on the tested cells (active area $0.39 \mathrm{~cm}^{2}$ ); however, the lower resistivity films could have significant benefit for larger cells where series resistance is prominent. Although a more detailed analysis of the films and their catalytic activities is forthcoming, we emphasize that highly conductive, catalytic, low-cost materials for flexible DSSCs which use FGS are already commercially available.

\section{CONCLUSIONS}

We used functionalized graphene sheets (FGSs) as a stand-alone catalyst in a dye-sensitized solar cell (DSSC) and demonstrated $\mathrm{FGS}_{13}$-based cells with efficiencies $\sim 10 \%$ lower than platinum-based cells. To explain this observation, we rigorously examined the catalytic activity of FGSs using electrochemical techniques. A new electrochemical impedance spectroscopy (EIS) equivalent circuit for porous carbon electrodes is proposed that accurately relates the observed impedance semicircles to their associated phenomena. Using this model, we determined that the charge-transfer resistance of FGS is 10 times greater than that of platinum at no applied bias and approaches that of platinum at applied bias. Cyclic voltammetry (CV) measurements showed that platinum has greater apparent catalytic activity compared to $\mathrm{FGS}_{13}$, as measured by the peak to peak separation $\left(E_{\mathrm{pp}}\right)$, which accounts for its lower charge-transfer resistance in DSSCs. We investigated the effect of tuning potentially catalytic functional groups on FGS and showed that increasing the number of oxygen-containing functional groups results in 
an increase of the material's apparent catalytic activity. We also recognized how fabricating a more porous FGS electrode could improve the apparent catalytic activity. Finally, we demonstrated that FGS-based inks cast on a nonconductive plastic substrate can be effectively used as a counter electrode, eliminating the need for a conductive substrate. Cells employing this versatile
FGS-ink flexible counter electrode performed $\sim 10 \%$ less efficiently than cells using platinum on a rigid fluorine-doped tin oxide glass (FTO) electrode. Tailoring the functionalization or morphology of the FGS electrodes could decrease their charge-transfer resistance and facilitate the low-cost production of catalytic, flexible, and conductive counter electrodes for DSSCs.

\section{EXPERIMENTAL METHODS}

Preparation of Counter Electrodes. For electrodes used in EIS and DSSCs, FGS counter electrodes were prepared on FTO (TEC8, Hartford Glass). FGS-surfactant (poly(ethylene oxide)poly(propylene oxide)-poly(ethylene oxide) triblock copolymer, F127, Pluronic) suspension (1.66 wt \% FGS, 1.66 wt \% F127 in water) was mixed in a poly(ethylene oxide) (PEO, $\left.M_{v} 600000\right)$ solution ( $0.6 \mathrm{~g}$ in $10 \mathrm{~mL}$ water, $10 \mathrm{~mL}$ ethanol) in a 1:4 FGS:PEO weight ratio and stirred overnight. The resulting suspension was spin coated onto clean FTO substrates at given speeds for $4 \mathrm{~min}$. The resulting film was dried at room temperature, and then the surfactants were thermally decomposed in an ashing furnace at $350{ }^{\circ} \mathrm{C}$ in air for $2 \mathrm{~h}$. Thermally treated chloroplatinic acid electrodes were prepared as described previously. ${ }^{8}$ Briefly, 2 $\mu \mathrm{L}$ of $5 \mathrm{mM}$ chloroplatinic acid in isopropanol was drop cast on an FTO electrode with a $0.39 \mathrm{~cm}^{2}$ mask. The sample was then heated to $380{ }^{\circ} \mathrm{C}$ for 20 min before use. FGS-based Vor-ink films were cast on mylar by Vorbeck Materials ${ }^{25}$ and used as received.

Electrodes for CV were prepared by drop casting an $\sim \mathrm{pH} 11$

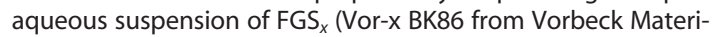
als) ${ }^{25}$ on the tips of titanium rods (grade 2 , diameter $=1 / 8$ inch, McMaster). Thermally treated chloroplatinic acid electrodes were also prepared using titanium rods. Combustion-based chemical analysis (Atlantic Microlab Inc., GA) was used to determine the $\mathrm{C} / \mathrm{O}$ ratio of the FGS samples. Titanium was selected as the electrode bulk material due to its high electrical conductivity, high corrosion resistance in the $\mathrm{I}^{-} / \mathrm{I}_{2}$ electrolyte solution, and low catalytic activity for the redox reaction of interest.

Preparation of DSSCs. DSSCs were constructed as described previously in the literature. ${ }^{3}$ In brief, $2 \mathrm{~g}$ of P25 titania nanoparticles (Evanonik) were suspended with $66 \mu \mathrm{L}$ of acetylacetone and $3.333 \mathrm{~mL}$ deionized water. Titania films, four layers thick, were cast on $\mathrm{TiCl}_{4}$ treated FTO glass using a scotch tape mask and a glass rod via the doctor blade technique. These films were then heated to $485^{\circ} \mathrm{C}$ for $30 \mathrm{~min}$ in air before being placed in a $0.2 \mathrm{M}$ $\mathrm{TiCl}_{4}$ solution for $12 \mathrm{~h}$ and heated to $450{ }^{\circ} \mathrm{C}$ for $30 \mathrm{~min}$. The resulting electrode was immersed in a $0.3 \mathrm{mM} \mathrm{N} 3$ dye/ethanol (Acros) solution for $20 \mathrm{~h}$ to form the sensitized photoanode. Platinum and FGS counter electrodes were formed as described above. A $25 \mu \mathrm{m}$ Surlyn film (Solaronix) was used to separate the photoanode and the counter electrode and to seal the cell after electrolyte (lodolyte AN-50 from Solaronix) was added. For the Vor-ink data series (Table 1 ), $\mathrm{TiCl}_{4}$ treatments were not performed. Also, due to the flexible nature of the Vor-ink films, to prevent short circuiting of the cells, the electrodes were separated by $100 \mu \mathrm{m}$ thick laboratory tape (Fisher) and clamped together using binder clips. Cells were tested immediately after fabrication.

All chemicals were electrochemical grade from Sigma Aldrich and used as received, unless otherwise noted.

Measurements. CV and EIS were performed using a Biologic SP150 potentiostat. The CV study was performed in a single compartment, three-electrode setup using an acetonitrile solution containing $0.1 \mathrm{M} \mathrm{LiClO}_{4}, 5 \mathrm{mM} \mathrm{Lil}$, and $0.5 \mathrm{mM} \mathrm{I}_{2}$. $\mathrm{A} \mathrm{Ag} / \mathrm{Ag}^{+}$reference electrode ( $0.01 \mathrm{M} \mathrm{AgNO}_{3}$ in acetonitrile) was used, and the cells were normalized to an external ferrocene reference. EIS was performed using a sandwich cell configuration with symmetric films in an acetonitrile electrolyte containing $0.5 \mathrm{M}$ Lil and $0.05 \mathrm{M} \mathrm{I}_{2}$ unless otherwise noted. A $25 \mu \mathrm{m}$ Surlyn film was used to separate the films and to seal the cells. EIS measurements were taken from 0 to $0.8 \mathrm{~V}$, the magnitude of the alternating signal was $10 \mathrm{mV}$, and the frequency range was $1 \mathrm{~Hz}$ to $400 \mathrm{kHz}$.
ZFit (Biologic), with the appropriate equivalent circuit, was used to analyze the impendence spectra. Current-voltage characteristics of DSSCs were taken under AM1.5G light, simulated at $100 \mathrm{~mW} / \mathrm{cm}^{2}$ with a $16 \mathrm{~S}$ solar simulator (SolarLight) using the potentiostat to apply various loads. Data values presented are the average of 2-6 identically prepared samples, while figures are representative of individual runs unless otherwise noted. The morphology of the electrodes was investigated by SEM (model 5130MM, Tescan) under $20 \mathrm{kV}$ accelerating voltage.

Acknowledgment. This work was supported by the Pacific Northwest National Laboratory (operated for the United States Department of Energy by Battelle) through Battelle grant no. 66354 and the Army Research Office (ARO)/Multidisciplinary Research Initiative (MURI) under grant no. W911NF-09-1-0476. J.R-M. received stipend support through the National Science Foundation Graduate Research Fellowship. The authors thank A. Bocarsly for his helpful discussions on the electrochemical aspects of this project and J. Lettow of Vorbeck Materials Corporation for supplying Vor-x and Vor-ink.

\section{REFERENCES AND NOTES}

1. O'Regan, B.; Grätzel, M. A Low-Cost, High-Efficiency Solar Cell Based on Dye-Sensitized Colloidal $\mathrm{TiO}_{2}$ Films. Nature 1991, 353, 737-740.

2. Grätzel, M. Solar Energy Conversion by Dye-Sensitized Photovoltaic Cells. Inorg. Chem. 2005, 44, 6841-6851.

3. Nazeeruddin, M. K.; Kay, A.; Rodicio, I.; Humphry-Baker, R.; Müller, E.; Liska, P.; Vlachopoulos, N.; Grätzel, M. Conversion of Light to Electricity by Cis- $\mathrm{X}_{2}$ bis(2,2' Bipyridyl-4,4'-Dicarboxylate)Ruthenium(II) Charge-Transfer Sensitizers ( $\mathrm{X}=\mathrm{Cl}^{-}, \mathrm{Br}^{-}, \mathrm{I}^{-}, \mathrm{CN}^{-}$, and $\left.\mathrm{SCN}^{-}\right)$on Nanocrystalline Titanium Dioxide Electrodes. J. Am. Chem. Soc. 1993, 115, 6382-6390.

4. Chiba, Y.; Islam, A.; Watanabe, Y.; Komiya, R.; Koide, N.; Han, L. Dye-Sensitized Solar Cells with Conversion Efficiency of 11.1\%. Jpn. J. Appl. Phys. 2006, 45, L638-L640.

5. Gao, F.; Wang, Y.; Zhang, J.; Shi, D.; Wang, M.; HumphryBaker, R.; Wang, P.; Zakeeruddin, S. M.; Grätzel, M. A New Heteroleptic Ruthenium Sensitizer Enhances the Absorptivity of Mesoporous Titania Film for a High Efficiency Dye-Sensitized Solar Cell. Chem. Commun. 2008, 2635-2637.

6. Bönnemann, H.; Khelashvili, G.; Behrens, S.; Hinsch, A.; Skupien, K.; Dinjus, E. Role of the Platinum Nanoclusters in the lodide/Triiodide Redox System of Dye Solar Cells. J. Cluster Sci. 2007, 18, 141-155.

7. Hauch, A.; Georg, A. Diffusion in the Electrolyte and Charge-Transfer Reaction at the Platinum Electrode in Dye-Sensitized Solar Cells. Electrochim. Acta 2001, 46, 3457-3466.

8. Papageorgiou, N.; Maier, W. F.; Grätzel, M. An lodine/Triiodide Reduction Electrocatalyst for Aqueous and Organic Media. J. Electrochem. Soc. 1997, 144, 876-884.

9. Lee, W. J.; Ramasamy, E.; Lee, D. Y.; Song, J. S. Performance Variation of Carbon Counter Electrode Based DyeSensitized Solar Cell. Sol. Energy Mater. Sol. Cells 2008, 92, 814-818.

10. Lindström, H.; Holmberg, A.; Magnusson, E.; Lindquist, S.- 
E.; Malmqvist, L.; Hagfeldt, A. A New Method for Manufacturing Nanostructured Electrodes on Plastic Substrates. Nano Lett. 2001, 1, 97-100.

11. Kay, A.; Grätzel, M. Low Cost Photovoltaic Modules Based on Dye Sensitized Nanocrystalline Titanium Dioxide and Carbon Powder. Sol. Energy Mater. Sol. Cells 1996, 44, 99-117.

12. Zhu, H.; Wei, J.; Wang, K.; Wu, D. Applications of Carbon Materials in Photovoltaic Solar Cells. Sol. Energy Mater. Sol. Cells 2009, 93, 1461-1470.

13. Chen, J.; Li, K.; Luo, Y.; Guo, X.; Li, D.; Deng, M.; Huang, S.; Meng, $\mathrm{Q}$. A Flexible Carbon Counter Electrode for DyeSensitized Solar Cells. Carbon 2009, 47, 2704-2708.

14. Huang, Z.; Liu, X.; Li, K.; Li, D.; Luo, Y.; Li, H.; Song, W.; Chen, L.; Meng, Q. Application of Carbon Materials as Counter Electrodes of Dye-Sensitized Solar Cells. Electrochem. Commun. 2007, 9, 596-598.

15. Easwaramoorthi, R.; Won Jae, L.; Dong Yoon, L.; Jae Sung, S. Nanocarbon Counterelectrode for Dye Sensitized Solar Cells. Appl. Phys. Lett. 2007, 90, 173103.

16. Trancik, J. E.; Barton, S. C.; Hone, J. Transparent and Catalytic Carbon Nanotube Films. Nano Lett. 2008, 8, 982987.

17. Suzuki, K.; Yamaguchi, M.; Kumagai, M.; Yanagida, S. Application of Carbon Nanotubes to Counter Electrodes of Dye-Sensitized Solar Cells. Chem. Lett. 2003, 32, 28-29.

18. Nam, J. G.; Park, Y. J.; Kim, B. S.; Lee, J. S. Enhancement of the Efficiency of Dye-Sensitized Solar Cell by Utilizing Carbon Nanotube Counter Electrode. Scr. Mater. 2010, 62, 148-150.

19. Murakami, T. N.; Grätzel, M. Counter Electrodes for Dsc: Application of Functional Materials as Catalysts. Inorg. Chim. Acta 2008, 361, 572-580.

20. Denaro, T.; Baglio, V.; Girolamo, M.; Antonucci, V.; Arico, A. S.; Matteucci, F.; Ornelas, R. Investigation of Low Cost Carbonaceous Materials for Application as Counter Electrode in Dye-Sensitized Solar Cells. J. Appl. Electrochem. 2009, 39, 2173-2179.

21. Xu, Y.; Bai, H.; Lu, G.; Li, C.; Shi, G. Flexible Graphene Films Via the Filtration of Water-Soluble Noncovalent Functionalized Graphene Sheets. J. Am. Chem. Soc. 2008, 130, 5856-5857.

22. Hong, W. J.; Xu, Y. X.; Lu, G. W.; Li, C.; Shi, G. Q. Transparent Graphene/Pedot-Pss Composite Films as Counter Electrodes of Dye-Sensitized Solar Cells. Electrochem. Commun. 2008, 10, 1555-1558.

23. Choi, H.; Kim, H.; Hwang, S.; Choi, W.; Jeon, M., DyeSensitized Solar Cells Using Graphene-Based Carbon Nano Composite as Counter Electrode. Sol. Energy Mater. Sol. Cells; DOI = 10.1016/j.solmat.2010.04.044

24. Fang, B.; Fan, S.-Q.; Kim, J. H.; Kim, M.-S.; Kim, M.; Chaudhari, N. K.; Ko, J.; Yu, J.-S. Incorporating Hierarchical Nanostructured Carbon Counter Electrode into Metal-Free Organic Dye-Sensitized Solar Cell. Langmuir 2010, 26 11238-11243.

25. Manufactured by Vorbeck Materials Corporation, Jessup, MD.

26. McAllister, M. J.; Li, J.-L.; Adamson, D. H.; Schniepp, H. C.; Abdala, A. A.; Liu, J.; Herrera-Alonso, M.; Milius, D. L.; Car, R.; Prud'homme, R. K.; Aksay, I. A. Single Sheet Functionalized Graphene by Oxidation and Thermal Expansion of Graphite. Chem. Mater. 2007, 19, 4396-4404.

27. Schniepp, H. C.; Li, J.-L.; McAllister, M. J.; Sai, H.; HerreraAlonso, M.; Adamson, D. H.; Prud'homme, R. K.; Car, R.; Saville, D. A.; Aksay, I. A. Functionalized Single Graphene Sheets Derived from Splitting Graphite Oxide. J. Phys. Chem. B 2006, 110, 8535-8539.

28. Kudin, K. N.; Ozbas, B.; Schniepp, H. C.; Prud'homme, R. K.; Aksay, I. A.; Car, R. Raman Spectra of Graphite Oxide and Functionalized Graphene Sheets. Nano Lett. 2007, 8, 36-41.

29. Schniepp, H. C.; Kudin, K. N.; Li, J.-L.; Prud'homme, R. K.; Car, R.; Saville, D. A.; Aksay, I. A. Bending Properties of Single Functionalized Graphene Sheets Probed by Atomic Force Microscopy. ACS Nano 2008, 2, 2577-2584.
30. Sato, K.; Saito, R.; Oyama, Y.; Jiang, J.; Cançado, L. G.; Pimenta, M. A.; Jorio, A.; Samsonidze, G. G.; Dresselhaus, G.; Dresselhaus, M. S. D-Band Raman Intensity of Graphitic Materials as a Function of Laser Energy and Crystallite Size. Chem. Phys. Lett. 2006, 427, 117-121.

31. Fang, X.; Ma, T.; Guan, G.; Akiyama, M.; Kida, T.; Abe, E. Effect of the Thickness of the Pt Film Coated on a Counter Electrode on the Performance of a Dye-Sensitized Solar Cell. J. Electroanal. Chem. 2004, 570, 257-263.

32. Wang, G.; Xing, W.; Zhuo, S. Application of Mesoporous Carbon to Counter Electrode for Dye-Sensitized Solar Cells. J. Power Sources 2009, 194, 568-573.

33. Peng, S.; Cheng, F.; Shi, J.; Liang, J.; Tao, Z.; Chen, J. HighSurface-Area Microporous Carbon as the Efficient Photocathode of Dye-Sensitized Solar Cells. Solid State Sci. 2009, 11, 2051-2055.

34. H Hamann, C. H.; Hamnett, A.; Vielstich, W. Electrochemistry; Wiley-VCH: New York, 1998.

35. Wang, D.; Choi, D.; Li, J.; Yang, Z.; Nie, Z.; Kou, R.; Hu, D.; Wang, C.; Saraf, L. V.; Zhang, J.; et al. Self-Assembled $\mathrm{TiO}_{2}$ Graphene Hybrid Nanostructures for Enhanced Li-lon Insertion ACS Nano; 2009, 3, 907-914.

36. Murakami, T. N.; Ito, S.; Wang, Q.; Nazeeruddin, M. K.; Bessho, T.; Cesar, I.; Liska, P.; Humphry-Baker, R.; Comte, P.; Pechy, P.; Grätzel, M. Highly Efficient Dye-Sensitized Solar Cells Based on Carbon Black Counter Electrodes. J. Electrochem. Soc. 2006, 153, A2255-A2261.

37. Li, P.; Wu, J.; Lin, J.; Huang, M.; Huang, Y.; Li, Q. HighPerformance and Low Platinum Loading Pt/Carbon Black Counter Electrode for Dye-Sensitized Solar Cells. Sol. Energy 2009, 83, 845-849.

38. Popov, A. I.; Geske, D. H. Studies of the Chemistry of Halogen and of Polyhalides. Xiii. Voltammetry of lodine Species in Acetonitrile. J. Am. Chem. Soc. 1958, 80.

39. Baucke, F. G. K.; Bertram, R.; Cruse, K. The lodide-lodine System in Acetonitrile: Evaluation of Standard Thermodynamic Data on the Association $\mathrm{I}^{-}+\mathrm{I}_{2} \rightarrow \mathrm{I}_{3}{ }^{-}$ from Potentiometric Measurements at 25 and $50^{\circ} \mathrm{C}$. J. Electroanal. Chem. 1971, 32, 247-256.

40. Boschloo, G.; Hagfeldt, A. Characteristics of the lodide/Triiodide Redox Mediator in Dye-Sensitized Solar Cells. Acc. Chem. Res. 2009, 42, 1819-1826.

41. Compton, R. G.; Banks, C. E. Understanding Voltammetry; World Scientific: Singapore, 2007.

42. Punckt, C.; Pope, M. A.; Liu, J.; Lin, Y.; Aksay, I. A., Electrochemical Performance of Graphene as Effected by Electrode Porosity and Graphene Functionalization. Electroanalysis 2010, 26; in press.

43. Austin, L. G. Porous Electrodes. In Comprehensive Treatise of Electrochemistry; Yaeger, E., Bockris, J. O. M., Conway, B. E., Sarangapani, S., Eds.; Plenum Press: New York, 1964; Vol. 6

44. Austin, L. G. Tafel Slopes for Flooded Diffusion Electrodes. Trans. Faraday Soc. 1964, 60, 1319-1324.

45. Menshykau, D.; Compton, R. G. The Influence of Electrode Porosity on Diffusional Cyclic Voltammetry. Electroanalysis 2008, 20, 2387-2394. 